\title{
Preparation of Two-Layer Anion-Exchange Poly(ethersulfone) Based Membrane: Effect of Surface Modification
}

\author{
Lucie Zarybnicka, ${ }^{1}$ Eliska Stranska, ${ }^{2}$ Jana Machotova, ${ }^{1}$ and Gabriela Lencova ${ }^{2}$ \\ ${ }^{1}$ Institute of Chemistry and Technology of Macromolecular Materials, Faculty of Chemical Technology, \\ University of Pardubice, Studentska 573, 53210 Pardubice, Czech Republic \\ ${ }^{2}$ MemBrain s.r.o., Pod Vinici 87, 47127 Straz pod Ralskem, Czech Republic \\ Correspondence should be addressed to Lucie Zarybnicka; zarybnicka.l@email.cz
}

Received 9 February 2016; Revised 31 March 2016; Accepted 11 April 2016

Academic Editor: Bencai Lin

Copyright (C) 2016 Lucie Zarybnicka et al. This is an open access article distributed under the Creative Commons Attribution License, which permits unrestricted use, distribution, and reproduction in any medium, provided the original work is properly cited.

The present work deals with the surface modification of a commercial microfiltration poly(ethersulfone) membrane by graft polymerization technique. Poly(styrene-co-divinylbenzene-co-4-vinylbenzylchloride) surface layer was covalently attached onto the poly(ethersulfone) support layer to improve the membrane electrochemical properties. Followed by amination, a two-layer anion-exchange membrane was prepared. The effect of surface layer treatment using the extraction in various solvents on membrane morphological and electrochemical characteristics was studied. The membranes were tested from the point of view of water content, ion-exchange capacity, specific resistance, permselectivity, FT-IR spectroscopy, and SEM analysis. It was found that the two-layer anion-exchange membranes after the extraction using tetrahydrofuran or toluene exhibited smooth and porous surface layer, which resulted in improved ion-exchange capacity, electrical resistance, and permselectivity of the membranes.

\section{Introduction}

Separation membranes have become an important part of chemical technology because of their growing industrial applications in the areas of separation and purification processes, biotechnology, nanotechnology, and membrane based energy devices. Ion-exchange membranes (IEMs) are among the most advanced types of separation membranes which are generally utilized as an active separator in diverse electrically driven processes. Energy saving, resource recovery, and pollution control are the main reasons for development of IEMs. Increasing the efficiency of a membrane is achieved in practice by an improvement of membrane permeability and selectivity at the same time. These two qualities are contradictory from the physical substance; nevertheless, new types of membranes are still being developed shifting the dependence of the selectivity on permeability (Robeson plot) to the upper right. One possibility is the preparation of a structurally modified multilayer membrane based on commercially available polymers $[1,2]$. The other way represents the utilization of polymer blends, in particular on the basis of semi-interpenetrating polymer networks [3-5]. In some cases, organic-inorganic hybrid membranes are reported, exhibiting increased physicochemical and electrochemical properties $[6,7]$.

In a study [8] organic-inorganic hybrid membrane (CEMS) has been studied which has been chemically modified in situ polymerization of aniline in an acidic medium using an oxidizing agent such as $\mathrm{FeCl}_{3}$. The presence of the polyaniline (PANI) on the surface and inside the membrane matrix was confirmed by scanning electron microscopy.

In the case of using the multilayer system, different characteristics of each layer are combined; thereby the desired combination of properties can be easily achieved. In the simplest arrangement, a two-layer system composed of the basic support layer and the highly separating surface layer can be applied. The purpose of the carrier layer is usually to ensure sufficient mechanical properties, minimal porosity, and sufficient permselectivity, whereas the surface layer should generally provide the maximum transport of ions from solution into the membrane phase, and vice versa. This layer should therefore have the highest possible conductivity. The surface 


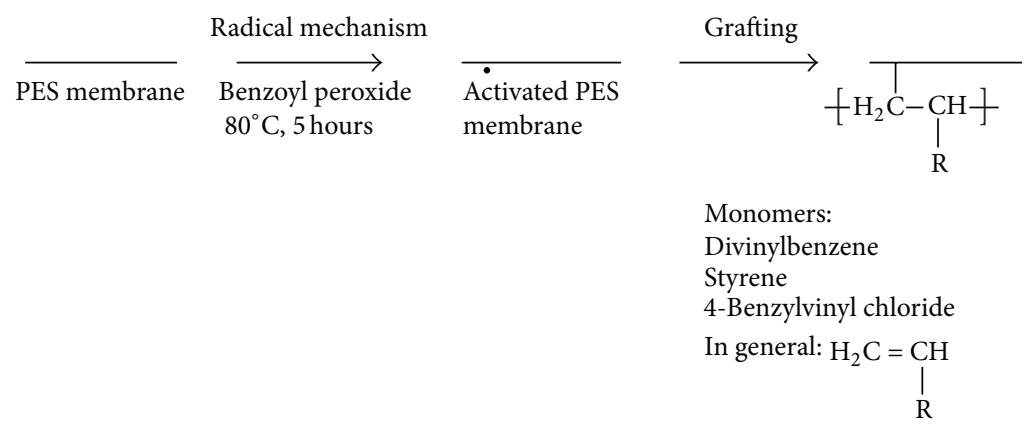

FIGURE 1: Radical and grafting mechanism of PES membrane [25].

layer can also be used as a separation means, for example, for a preferential transport of univalent ions from multivalent, or as a means for reducing the impact of fouling [9].

In recent years, the role of surface characteristics in determining the separation properties of membranes is obvious [10-14]. Different methods such as graft polymerization $[15,16]$, plasma modification $[17,18]$, corona discharge, and flame treatment [19] have been utilized in membrane surface modification to alter the physical and chemical properties of membranes without affecting the bulk properties. Hong et al. $[20,21]$ prepared a positively charged nanofiltration (NF) membrane using the ultrafiltration membrane as a support layer and the quaternized chitosan as an active layer by the method of cross-linking. The obtained membrane showed high rejection of $\mathrm{MgCl}_{2}$ and low rejection of $\mathrm{Na}_{2} \mathrm{SO}_{4}$, and the positively charged characteristic of the NF membranes was demonstrated. Kikhavani et al. [22-24] cross-linked polyimide substrate with hyperbranched polyethyleneimine and obtained a stably attached layer on the membrane surface showing positively charged surface properties.

In the current research, the surface modification of a commercial microfiltration membrane was carried out to achieve efficient electrochemical properties useful in electrodialysis processes. Two-layer polymeric membranes were composed of a porous poly(ethersulfone) (PES) support layer, which is a commercially available material commonly used for microfiltration and dialysis membrane production, and an anionexchange surface polymeric layer based on poly(styrene-codivinylbenzene-co-4-vinylbenzylchloride). Followed by amination, the two-layer anion-exchange membranes (AEMs) were prepared. The effect of surface layer treatment using extraction by commonly utilized solvents on morphological and electrochemical characteristics of the membranes was studied. The membranes were tested from the point of view of water content, ion-exchange capacity (IEC), specific resistance, permselectivity, FT-IR spectroscopy, and SEM analysis.

\section{Experimental Part}

2.1. Materials. Materials were as follows: PES microfiltration membrane MT (Synder, USA), divinylbenzene (DVB) (Sigma-Aldrich, purity 80\%), styrene (St) (Sigma-Aldrich, purity 99.9\%), 4-vinylbenzylchloride (VBC) (Sigma-Aldrich,
TABLE 1: Composition of reaction mixture for surface modification of PES membrane.

\begin{tabular}{lcccc}
\hline \multirow{2}{*}{ Surface layer } & \multicolumn{4}{c}{ Reaction mixture (wt.\%) } \\
& VBC & DVB & BP & St \\
\hline 1 & 48.7 & 16.20 & 2.60 & 32.50 \\
2 & 55.9 & 4.40 & 2.90 & 36.80 \\
\hline
\end{tabular}

purity 90\%), benzoyl peroxide (BP) (Sigma-Aldrich, 75\% remainder water), tetrahydrofuran (THF), chloroform and toluene (Penta Chemicals, Czech Republic, purity 99.8\%), and trimethylamine (TMA) (Sigma-Aldrich, $45 \mathrm{wt} . \%$ in $\left.\mathrm{H}_{2} \mathrm{O}\right)$.

2.2. Surface Modification. The surface modification of PES membranes consisted in grafting (Figure 1) a polymeric surface layer of poly(styrene-co-divinylbenzene-co-4-vinylbenzylchloride) onto a commercial PES membrane support layer. In the first step, the PES membrane was cleaned overnight using distilled water and subsequently dried at $50^{\circ} \mathrm{C}$ to constant weight. Then the membrane was immersed in the mixture of monomers (St, DVB, and VBC) that were copolymerized in the presence of $\mathrm{BP}$ initiator. The reaction proceeded at $80^{\circ} \mathrm{C}$ for $5 \mathrm{~h}$. The composition of monomer mixture is listed in Table 1. After that, the morphology of the prepared surface modified membrane was tailored by Soxhlet extraction using different extraction media, namely, THF, toluene, chloroform, and distilled water. The extraction was terminated after 72 hours and amination of the surface modified PES membrane was performed for introducing anionexchange functionalities by using $45 \mathrm{wt} \%$ TMA in $\mathrm{H}_{2} \mathrm{O}$ (Figure 2). The amination proceeded at room temperature for $24 \mathrm{~h}$, followed by conditioning in $1 \mathrm{M} \mathrm{NaOH}$ for 24 hours, washing with distilled water, and subsequent conditioning in $1 \mathrm{M} \mathrm{HCl}$.

\subsection{Membrane Characterization}

2.3.1. Morphological Studies. The surface morphologies of prepared membranes were examined by scanning electron microscope QUANTA FEG 450 using ESEM mode. The samples were chrome plated. 

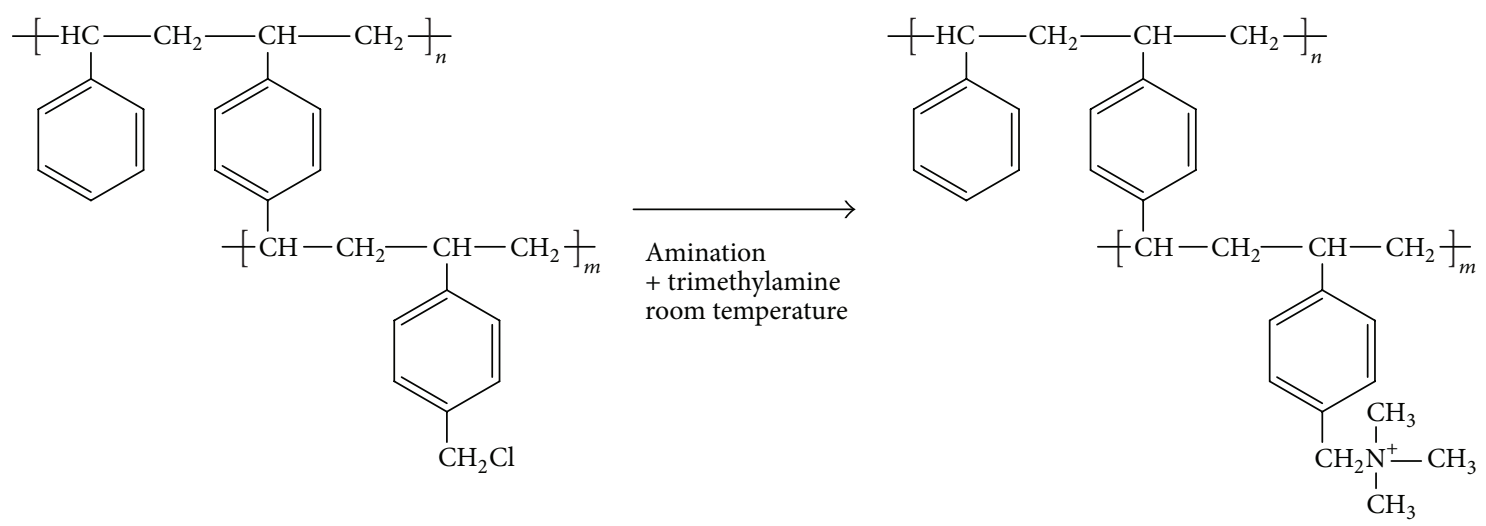

Figure 2: Amination of poly(styrene-co-divinylbenzene-co-4-vinylbenzylchloride) surface layer using TMA.

2.3.2. FT-IR Spectroscopy. The membranes were characterized by infrared spectroscopy on a modular instrument IS50 FT-IR (Nicolet companies). The reflective technology ATR (IS50 ATR) equipped with diamond crystal, KBr beam splitter, InGaAs detector $2.6 \mu \mathrm{m}$, IR radiation source, $\mathrm{HeNe}$ reference laser, and linear scan Vectra $^{\mathrm{Tm}}$ interferometer was used. The resolution was $2 \mathrm{~cm}^{-1}$ and the spectrum was integrated from 64 scans. The measurements were performed in the range from $4000 \mathrm{~cm}^{-1}$ to $400 \mathrm{~cm}^{-1}$. The resulting spectra were processed using a conversion algorithm ATR correction on the transmission spectrum based on the input data: the angle of incidence of $45^{\circ}$.

2.3.3. Water Content and Ion-Exchange Capacity (IEC). Before measuring the water content, a membrane sample was vacuum-dried at $100^{\circ} \mathrm{C}$ until the constant weight was obtained. Then the membrane was left to swell in demineralized water for 12 hours and after wiping the free water with filter paper rapidly and carefully, the membrane was weighed immediately. After conditioning in $\mathrm{Cl}^{-}$cycles, IEC of an IEM was determined in the following manner: $1 \mathrm{~g}$ of the membrane sample was treated with $50 \mathrm{~mL}$ of $4 \% \mathrm{NaNO}_{3}$ and then the sample was left on a shaker for 1 hour at room temperature. Thereafter, for the actual determination, $10 \mathrm{~mL}$ of the solution was pipetted and diluted to $30 \mathrm{~mL}$ with demineralized water and the sample was titrated with $0.1 \mathrm{M} \mathrm{AgNO}_{3}$ and the equivalence point was determined using $\mathrm{K}_{2} \mathrm{CrO}_{4}$ indicator. IEC of the IEM per gram of dry matter was calculated using the following relation:

$$
\mathrm{IEC}=\frac{\left(\left(C_{\mathrm{AgNO}_{3}} \times V_{\mathrm{AgNO}_{3}}\right) / V_{\mathrm{NaNO}_{3}}^{I}\right) \times V_{\mathrm{NaNO}_{3}}}{m},
$$

where $V_{\mathrm{AgNO}_{3}}$ is the volume of $\mathrm{AgNO}_{3}$ solution, $C_{\mathrm{AgNO}_{3}}$ is the concentration of $\mathrm{AgNO}_{3}$ solution, $V_{\mathrm{NaNO}_{3}}^{I}$ is the consumed amount of the solution for titration $(10 \mathrm{~mL}), V_{\mathrm{NaNO}_{3}}$ is the added amount of $0.1 \mathrm{M} \mathrm{NaNO}_{3}(50 \mathrm{~mL})$, and $m$ is the weight of dried membrane sample.

2.3.4. Electrical Resistance and Permselectivity. The electrical resistance is practically important due to its relation with energy consumption in the process. Before the measurement of the specific resistance $\left(R_{s}\right)$ and the areal resistance $\left(R_{A}\right)$ of a membrane, a membrane sample was equilibrated in a solution of $0.5 \mathrm{M} \mathrm{NaCl}$ for 24 hours. The resistance was measured at room temperature in $0.5 \mathrm{M} \mathrm{NaCl}$ in the test cell using a compensation method. The test cell consisted of two parts which are separated from one another by the IEM sample. Constant direct current of $10 \mathrm{~mA}$ was set between interposed platinum electrodes and voltage was measured between reference calomel electrodes at $25^{\circ} \mathrm{C}$. The specific resistance was determined according to the following relationship:

$$
R_{s}=\frac{\left(U_{\mathrm{IM}+\mathrm{sol}}-U_{\mathrm{sol}}\right)}{I} \cdot \frac{S}{\mathrm{th}},
$$

where $R_{s}$ is the specific resistance of IEM, $U_{\mathrm{IM}+\text { sol }}$ is the potential of a solution with the embedded IEM sample, $U_{\text {sol }}$ is the potential of a solution without inserting IEM sample, $I$ is the direct current, $S$ is the active area of IEM sample of $0.785 \mathrm{~cm}^{2}$, and th is the thickness of IEM sample.

The areal resistance was determined using the following relationships:

$$
\begin{aligned}
& R_{A}=\left(R_{j}^{r+r}-R^{r}\right) A, \\
& R_{r} \\
& \quad=\frac{\left|U_{\text {meas }}(1,2)-U_{\text {as }}^{r}(2,2)\right|_{j}+\left|U_{\text {meas }}(2,1)-U_{\text {as }}^{r}(2,1)\right|_{j}}{2 I},
\end{aligned}
$$

where $U_{\text {as }}$ is the asymmetric voltage and $U_{\text {meas }}$ is the measured voltage.

The permselectivity $(P)$ was determined using method of Henderson [26]. Membrane samples were equilibrated in $0.5 \mathrm{M} \mathrm{KCl}$ for 24 hours before the measurement. 0.1 and $0.5 \mathrm{M}$ $\mathrm{KCl}$ solution were poured into separate parts of the test cell. Permselectivity was subsequently determined according to the following relationship:

$$
P=\frac{U_{\text {meas }}}{U_{\text {teor }}} \times 100(\%),
$$

where $U_{\text {meas }}$ is the measured voltage and $U_{\text {teor }}$ is the theoretical voltage based on Nernst's law expressed by relationship 


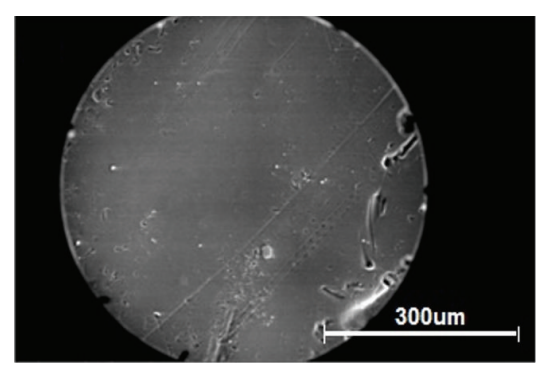

(a)

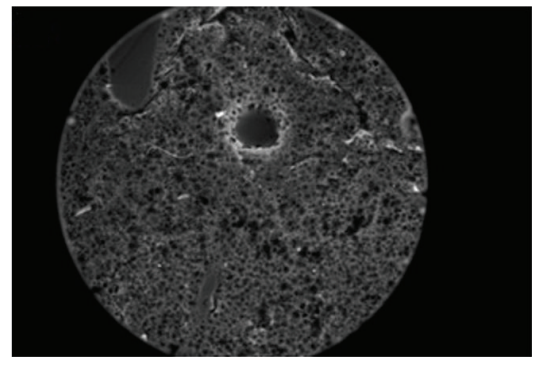

(d)

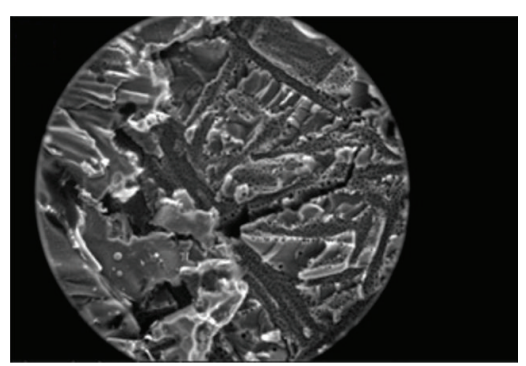

(b)

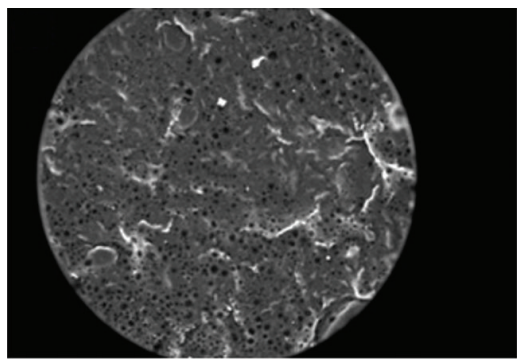

(e)

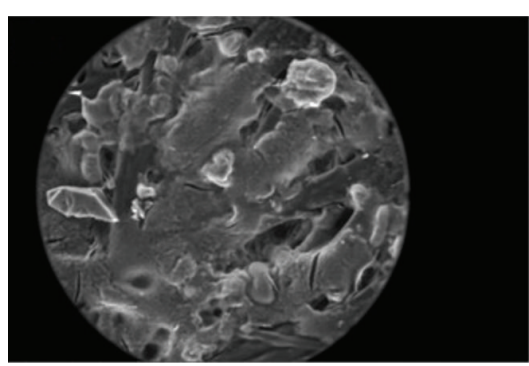

(c)

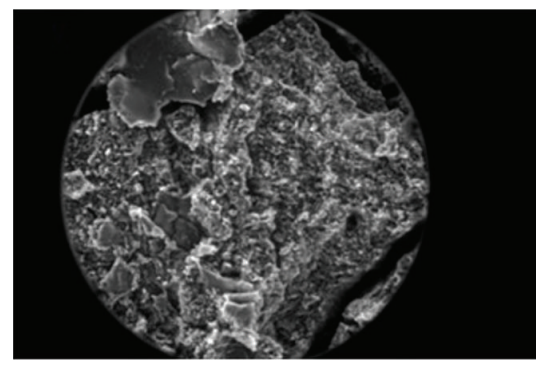

(f)

FIGURE 3: The SEM surface images (500x magnification) of treated membranes using different extraction solvents: (a) PES membrane without modification and extraction treatment, (b) AEM coated with surface on membrane 1 after the extraction in chloroform, (c) AEM coated with surface on membrane 2 after the extraction in chloroform, (d) AEM coated with surface on membrane 1 after the extraction in toluene, (e) AEM coated with surface on membrane 2 after the extraction in toluene, and (f) AEM coated with surface on membrane 1 after the extraction in THF.

(5), with regard to the activity of cations $a_{K 1}, a_{K 2}$ and anions $a_{\mathrm{A} 1}, a_{\mathrm{A} 2}$ in $\mathrm{KCl}$ solution present in separate parts of the test:

$$
U_{\text {teor }}=-\frac{R T}{2 F} \times \ln \frac{a_{K 1} \times a_{A 1}}{a_{K 2} \times a_{A 2}},
$$

where $R$ is the universal gas constant $=8.3145 \mathrm{~J} / \mathrm{mol} \mathrm{K}, T$ is temperature $(\mathrm{K})$, and $F$ is the Faraday constant $=$ $96485 \mathrm{C} \mathrm{mol}^{-1}$.

\section{Results and Discussion}

3.1. Surface Morphology of Two-Layer Membranes. Two polymeric systems were used as surface modifiers of the commercial microfiltration PES membrane resulting in the preparation of two-layer polymeric membranes. The polymeric systems differed especially in cross-linking density due to different amounts of DVB. The purpose of the support layer formed by PES microfiltration membrane is to ensure mechanical properties as well as good transport properties due to increased porosity, whereas the grafted surface layer should serve mainly as a separation means, providing transport of ions into the membrane phase and ensuring the selectivity of the resulting membrane as well.

To remove unreacted compounds and to tailor the porosity and surface morphology of the grafted copolymer separation layer, the extraction of surface modified two-layer membranes was carried out using different solvents, namely, THF, toluene, chloroform, and water. It was found that PES membrane integrity remained unaffected after carrying out the extraction in THF, toluene, and water, but not all
TABLE 2: Effect of extraction treatment using various solvents on the amount of extracted compounds.

\begin{tabular}{lcc}
\hline $\begin{array}{l}\text { Surface on } \\
\text { membrane }\end{array}$ & Extracting solvent & $\begin{array}{c}\text { Surface on AEM PES } \\
\text { membrane after extraction } \\
\text { (wt.\%) }\end{array}$ \\
\hline \multirow{3}{*}{1} & Chloroform & 32.99 \\
& Water & 72.18 \\
& Tetrahydrofuran & 63.32 \\
& Toluene & 64.05 \\
\hline \multirow{4}{*}{2} & Chloroform & 28.16 \\
& Water & 73.94 \\
& Tetrahydrofuran & 56.75 \\
& Toluene & 46.17 \\
\hline
\end{tabular}

unreacted compounds are supposed to be removed, especially in the case of water extraction, which was demonstrated by gravimetrical measurements (see Table 2). In the case of using chloroform as the extraction media, both the surface layer and the PES support layer were damaged during the extraction process, which was manifested clearly by SEM measurements (Figures 3 and 4 ).

It is well known that the membrane performance is strongly dependent on its surface and morphology. The effect of extraction treatment on AEMs surface morphology is shown in Figures 3 and 4. It is evident that the surfaces of the membranes were changed by extraction treatment. The membranes after the extraction using chloroform exhibited 


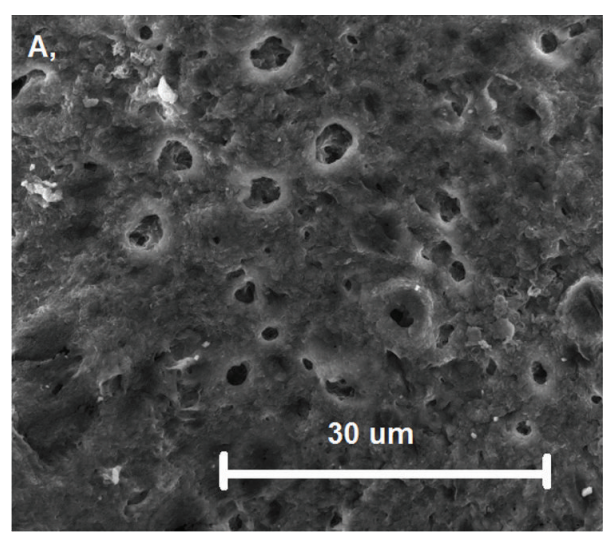

(a)

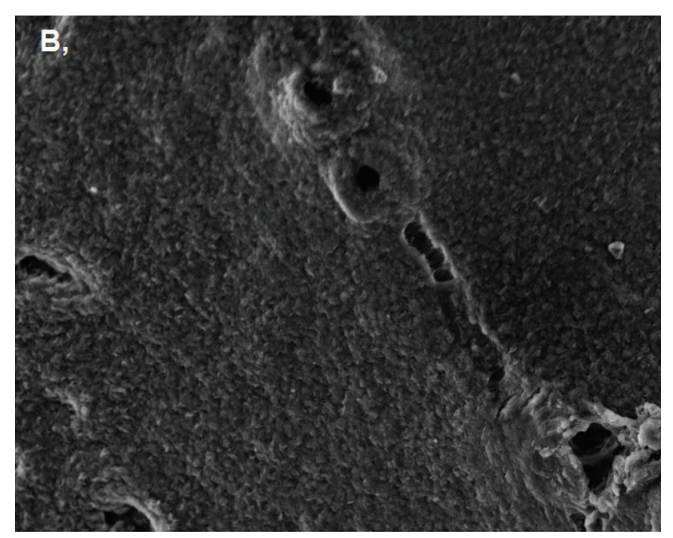

(b)

FIGURE 4: The SEM surface images (5000x magnification) of treated membranes using different extraction solvents: (a) AEM coated with surface on membrane 1 after the extraction in THF and (b) AEM coated with surface on membrane after the extraction in THF.

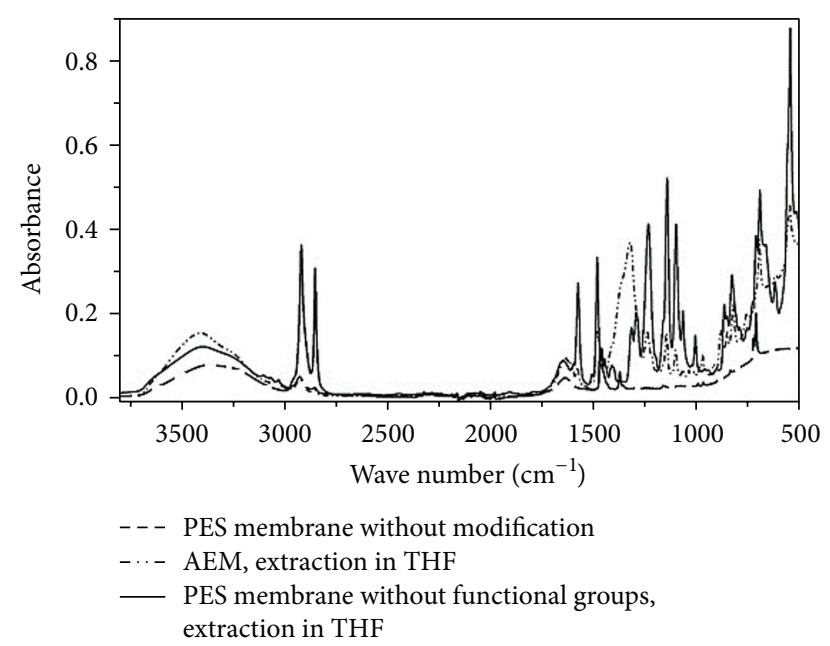

FIGURE 5: FT-IR spectra of PES membrane without modification, surface modified PES membrane without amino functionalities, and the surface PES AEM, the latter two types of membranes coated with surface layer 2 and treated with THF extraction.

rough and damaged surface (see Figure 3), whereas the surface structure of AEMs tailored with water, toluene, and THF extraction exhibited relatively smooth and uniform character with regularly distributed pores. Thus, assuming that the pores generate easy flow channels for the counter-ion transportation, the two-layer AEM treated particularly by toluene or THF extraction may provide favorable ionic conducting performance with improved electrochemical characteristics and decreased impact on the polarization phenomenon.

FT-IR spectroscopy was carried out for comparing the PES membrane without modification, the surface modified membrane without amino functionalities, and the AEM, the latter two membranes coated with surface on membrane 2 and treated using THF extraction (see Figure 5). The peaks assigned to aromatic groups were shown at $1630 \mathrm{~cm}^{-1}$ and
TABLE 3: The results of water content and IEC of anion-exchange hybrid PES membranes.

\begin{tabular}{lccc}
\hline $\begin{array}{l}\text { Surface on } \\
\text { membrane }\end{array}$ & Extracting solvent & $\begin{array}{c}\text { Water content } \\
\text { (wt.\%) }\end{array}$ & $\begin{array}{c}\text { IEC (meq/g dry } \\
\text { matter) }\end{array}$ \\
\hline \multirow{4}{*}{1} & Chloroform & 2.4 & 0.79 \\
& Water & 9.4 & 1.59 \\
& Tetrahydrofuran & 5.1 & 1.22 \\
& Toluene & 5.1 & 1.6 \\
\hline \multirow{3}{*}{2} & Chloroform & 4.6 & 0.8 \\
& Water & 7.4 & 1.84 \\
& Tetrahydrofuran & 13.2 & 1.63 \\
& Toluene & 11.2 & 2.1 \\
\hline
\end{tabular}

$1490 \mathrm{~cm}^{-1}$ and those of quaternary ammonium group at 980, 898 , and $812 \mathrm{~cm}^{-1}$. It is evident from the curve corresponding to the AEM that the surface layer containing ion-exchange amino functionalities was covalently grafted on the support PES membrane even after performing THF extraction.

3.2. Water Content and Electrochemical Properties. Determination of water content is of great importance in terms of applicability of the ion-exchange resin. Water assists the transportation of ions from the anode to the cathode. Hence, IEMs should absorb sufficient water, whereas excessive water absorption will induce the loss of dimensional stability and mechanical properties [27]. With a higher water content value, increased conductivity can be expected, which is connected with higher affinity to ions [28].

Table 3 summarizes the results of water content measurements. The lowest values of water content were found in the case of samples extracted with chloroform. As mentioned above, these samples exhibited damaged surface layer as well as the support layer after the extraction in chloroform. When comparing both types of surface layers, surface layer 1 modified AEMs absorbed lower amounts of water. 
TABLE 4: Ion-exchange capacity, areal resistance, specific resistance, and membrane thickness averages for the prepared surface modified PES membranes before and after amination.

\begin{tabular}{|c|c|c|c|c|c|c|c|}
\hline \multirow{2}{*}{$\begin{array}{l}\text { Surface on } \\
\text { membrane }\end{array}$} & \multirow{2}{*}{ Extracting solvent } & \multicolumn{3}{|c|}{ Two-layer membrane without amination } & \multicolumn{3}{|c|}{ AEM membrane } \\
\hline & & Thickness $(\mu \mathrm{m})$ & $R_{A}\left(\Omega \cdot \mathrm{cm}^{2}\right)$ & $R_{s}(\Omega \cdot \mathrm{cm})$ & Thickness $(\mu \mathrm{m})$ & $R_{A}\left(\Omega \cdot \mathrm{cm}^{2}\right)$ & $R_{s}(\Omega \cdot \mathrm{cm})$ \\
\hline \multirow{4}{*}{1} & Chloroform & 306 & 143.93 & 3378.70 & 337 & 2.43 & 90.00 \\
\hline & Water & 283 & 144.39 & 5102.20 & 366 & 13.48 & 368.20 \\
\hline & THF & 284 & 144.38 & 5083.90 & 386 & 5.2 & 179.00 \\
\hline & Toluene & 307 & 51.04 & 1254.00 & 575 & 11.69 & 346.90 \\
\hline \multirow{5}{*}{2} & Chloroform & 307 & 25.87 & 842.80 & 338 & 0.88 & 53.00 \\
\hline & Water & 307 & 143.78 & 4683.50 & 443 & 3.53 & 79.60 \\
\hline & THF & 325 & 24.92 & 797.80 & 436 & 1.92 & 49.00 \\
\hline & Toluene & 306 & 144.05 & 4707.70 & 445 & 1.66 & 38.10 \\
\hline & $\begin{array}{c}\text { PES membrane } \\
\text { without modification }\end{array}$ & 196 & 2.53 & 129.10 & & & \\
\hline
\end{tabular}

The possible explanation of this behavior is the increased cross-linking density of surface layer 1 copolymer comprising higher amount of DVB units.

To evaluate the functionality of AEMs, IEC was chosen as an evaluative property. The ion-exchange capacity refers to a number of ions that the system is able to bind and it is known to have the profound effects on many important properties of ion-exchange membranes, such as the water swellability [29]. The results of IEC are shown in Table 3. It can be seen that the surface modified AEMs coated with polymeric layer 1 possessed the highest value of IEC of $1.60 \mathrm{meq} / \mathrm{g}$ in the case of performing the extraction in toluene, whereas the lowest value of IEC of $0.79 \mathrm{meq} / \mathrm{g}$ was achieved after the extraction using chloroform. For AEMs modified by polymeric system 2, the maximum value of the IEC of $2.10 \mathrm{meq} / \mathrm{g}$ was maintained after the extraction with toluene as well. This fact can be attributed to the presence of pores in the toluene-treated surface layer structure which act as flow channels for the counter-ion transportation. The lowest IEC of $0.80 \mathrm{meq} / \mathrm{g}$ was observed in the case of chloroform extraction, which corresponds to the loss of ion-exchange surface layer by chloroform extraction.

The electric resistance for surface modified PES membranes without amination and for AEMs (after introducing functional amino groups) was examined (see Table 4). It was shown that all surface modified two-layer membranes without amination exhibited extremely high values of areal and specific resistance $\left(R_{A}\right.$ and $\left.R_{s}\right)$ in contrast to AEMs, which indicates that the porous PES support layer (exhibiting relatively low electric resistance owing to the porous character) was sufficiently coated with a compact insulating polymer surface layer. After introducing polar amino functionalities, the conductivity of the two-layer modified membranes increased significantly. According to results of electric resistance, the most convenient electric properties were found for the surface modified AEMs coated with surface layer 2 and treated with THF or toluene extraction. The improved electric properties are probably connected by both the porous character and the increased mobility of the covalently grafted surface layer copolymer (due to lower network density), both phenomena leading to improved ion transport.
TABLE 5: Results of permselectivity for two-layer AEMs differing in surface layer type and extraction treatment.

\begin{tabular}{lcc}
\hline Surface on membrane & Extracting solvent & Permselectivity (\%) \\
\hline \multirow{4}{*}{1} & Chloroform & 2.6 \\
& Water & 66.3 \\
& Tetrahydrofuran & 73.2 \\
& Toluene & 80.4 \\
\hline \multirow{4}{*}{2} & Chloroform & 1.1 \\
& Water & 67.4 \\
& Tetrahydrofuran & 84.5 \\
\hline
\end{tabular}

Permselectivity for the two-layer AEMs was investigated as well. Permselectivity indicates the proportion of the charge transferred from the counter ions to the total transferred charge [30]. The results reveal (see Table 5) that, after performing chloroform extraction, the membranes exhibited low permselectivity, whereas the surface layer treatment by toluene extraction or THF extraction provided high permselectivity. Low values of permselectivity in the case of AEMs treated with chloroform extraction suggest a significant surface layer removal.

\section{Conclusion}

Two-layer AEMs based on a commercial PES microfiltration membrane were successfully prepared by grafting a polymeric surface layer of poly(styrene-co-divinylbenzene-co-4vinylbenzylchloride) onto the PES membrane support layer.

The surface morphology of the grafted copolymer separation layer was affected by the extraction using different solvents, namely, THF, toluene, chloroform, and water. It was shown that the membranes after the extraction using chloroform exhibited rough and damaged surface layer, whereas the surface layer of AEMs treated with THF or toluene extraction was relatively smooth with regularly distributed pores. In contrast to chloroform-treated AEMs, the AEMs comprising 
THF or toluene-treated surface layer showed improved ionexchange capacity, electrical resistance, and permselectivity, which can be attributed mainly to the presence of pores acting as flow channels for the counter-ion transportation. Thus, the surface layer treatment producing different surface morphology and porosity was shown to play a crucial role in membrane performance and two-layer membranes exhibiting both high permeability and permselectivity can be successfully prepared by tailoring the surface layer porosity. These membranes can find their application in electrodialytic processes.

\section{Competing Interests}

The authors declare that they have no competing interests.

\section{Acknowledgments}

The work was carried out within the framework of Project no. LO1418 "Progressive Development of Membrane Innovation Centre" supported by the program NPU I of Ministry of Education, Youth and Sports of the Czech Republic, using the infrastructure Membrane Innovation Centre.

\section{References}

[1] M. Wang, X.-L. Wang, Y.-X. Jia, and X. Liu, "An attempt for improving electrodialytic transport properties of a heterogeneous anion exchange membrane," Desalination, vol. 351, pp. 163-170, 2014.

[2] X.-L. Wang, M. Wang, Y.-X. Jia, and B.-B. Wang, "Surface modification of anion exchange membrane by covalent grafting for imparting permselectivity between specific anions," Electrochimica Acta, vol. 174, pp. 1113-1121, 2015.

[3] Y. Mizutani, "Structure of ion exchange membranes," Journal of Membrane Science, vol. 49, no. 2, pp. 121-144, 1990.

[4] G. Pozniak and W. Trochimczuk, "Tubular interpolymer ion exchange membranes," Die Angewandte Makromolekulare Chemie, vol. 127, pp. 171-186, 1984.

[5] S. S. Madaeni, S. Amirinejad, and M. Amirinejad, "Phosphotungstic acid doped poly(vinyl alcohol)/poly(ether sulfone) blend composite membranes for direct methanol fuel cells," Journal of Membrane Science, vol. 380, no. 1-2, pp. 132-137, 2011.

[6] Y. Song, X. Cao, Q. Liang et al., "Sulfonated polyimides and their polysilsesquioxane hybrid membranes for fuel cells," Solid State Ionics, vol. 258, pp. 92-100, 2014.

[7] H. Beydaghi, M. Javanbakht, and A. Badiei, "Cross-linked poly(vinyl alcohol)/sulfonated nanoporous silica hybrid membranes for proton exchange membrane fuel cell," Journal of Nanostructure in Chemistry, vol. 4, article 97, 2014.

[8] M. Kumar, M. A. Khan, Z. A. AlOthman, and M. R. Siddiqui, "Polyaniline modified organic-inorganic hybrid cationexchange membranes for the separation of monovalent and multivalent ions," Desalination, vol. 325, pp. 95-103, 2013.

[9] Y. Zhou, S. Yu, C. Gao, and X. Feng, "Surface modification of thin film composite polyamide membranes by electrostatic self deposition of polycations for improved fouling resistance," Separation and Purification Technology, vol. 66, no. 2, pp. 287294, 2009.
[10] Z. Xu, J. Wang, L. Shen, D. Men, and Y. Xu, "Microporous polypropylene hollow fiber membrane: part I. Surface modification by the graft polymerization of acrylic acid," Journal of Membrane Science, vol. 196, no. 2, pp. 221-229, 2002.

[11] D. R. Lloyd, Ed., Material Science of Synthetic Membranes, ACS Symposium Series 269, chapter 1, American Chemical Society, Washington, DC, USA, 1985.

[12] W. R. Bowen, N. Hilal, R. W. Lovitt, and C. J. Wright, "Characterisation of membrane surfaces: direct measurement of biological adhesion using an atomic force microscope," Journal of Membrane Science, vol. 154, no. 2, pp. 205-212, 1999.

[13] S. M. Hosseini, B. Rahzani, H. Asiani et al., "Surface modification of heterogeneous cation exchange membranes by simultaneous using polymerization of (acrylic acid-co-methyl methacrylate): membrane characterization in desalination process," Desalination, vol. 345, pp. 13-20, 2014.

[14] R. Ibanez, D. F. Stamatialis, and M. Wessling, "Role of membrane surface in concentration polarization at cation exchange membranes," Journal of Membrane Science, vol. 239, no. 1, pp. 119-128, 2004.

[15] S. S. Madaeni, S. Zinadini, and V. Vatanpour, "A new approach to improve antifouling property of PVDF membrane using in situ polymerization of PAA functionalized $\mathrm{TiO}_{2}$ nanoparticles," Journal of Membrane Science, vol. 380, no. 1-2, pp. 155-162, 2011.

[16] P. Daraei, S. S. Madaeni, N. Ghaemi, H. Ahmadi Monfared, and M. A. Khadivi, "Fabrication of PES nanofiltration membrane by simultaneous use of multi-walled carbon nanotube and surface graft polymerization method: comparison of MWCNT and PAA modified MWCNT," Separation and Purification Technology, vol. 104, pp. 32-44, 2013.

[17] S. M. Hosseini, S. S. Madaeni, A. R. Khodabakhshi, and A. Zendehnam, "Preparation and surface modification of PVC/SBR heterogeneous cation exchange membrane with silver nanoparticles by plasma treatment," Journal of Membrane Science, vol. 365, no. 1-2, pp. 438-446, 2010.

[18] S. M. Hosseini, S. S. Madaeni, A. Zendehnam, A. R. Moghadassi, A. R. Khodabakhshi, and H. Sanaeepur, "Preparation and characterization of PVC based heterogeneous ion exchange membrane coated with Ag nanoparticles by (thermal-plasma) treatment assisted surface modification," Journal of Industrial and Engineering Chemistry, vol. 19, no. 3, pp. 854-862, 2013.

[19] C. M. Chan, Polymer Surface Modification and Characterization, Hanser (Carl), Munich, Germany, 1994.

[20] S. U. Hong, R. Malaisamy, and M. L. Bruening, "Optimization of flux and selectivity in $\mathrm{Cl}^{-} / \mathrm{SO}_{4}^{2-}$ separations with multilayer polyelectrolyte membranes," Journal of Membrane Science, vol. 283, no. 1-2, pp. 366-372, 2006.

[21] M. C. Martí-Calatayud, D. C. Buzzi, M. García-Gabaldón, A. M. Bernardes, J. A. S. Tenório, and V. Pérez-Herranz, "Ion transport through homogeneous and heterogeneous ion-exchange membranes in single salt and multicomponent electrolyte solutions," Journal of Membrane Science, vol. 466, pp. 45-57, 2014.

[22] T. Kikhavani, S. N. Ashrafizadeh, and B. van der Bruggen, "Nitrate selectivity and transport properties of a novel anion exchange membrane in electrodialysis," Electrochimica Acta, vol. 144, pp. 341-351, 2014.

[23] M. Wang, Y.-X. Jia, T.-T. Yao, and K.-K. Wang, "The endowment of monovalent selectivity to cation exchange membrane by photo-induced covalent immobilization and self-crosslinking of chitosan," Journal of Membrane Science, vol. 442, pp. 39-47, 2013. 
[24] W. J. Tong, C. Gao, and H. Möhwald, "Poly(ethyleneimine) microcapsules: glutaraldehyde-mediated assembly and the influence of molecular weight on their properties," Polymers for Advanced Technologies, vol. 19, no. 7, pp. 817-823, 2008.

[25] M. M. Nasef and E.-S. A. Hegazy, "Preparation and applications of ion exchange membranes by radiation-induced graft copolymerization of polar monomers onto non-polar films," Progress in Polymer Science, vol. 29, no. 6, pp. 499-561, 2004.

[26] W. Cui, J. Kerres, and G. Eigenberger, "Development and characterization of ion-exchange polymer blend membranes," Separation and Purification Technology, vol. 14, no. 1-3, pp. 145-154, 1998.

[27] S. Zhong, X. Cui, S. Dou, and W. Liu, "Preparation and characterization of self-crosslinked organic/inorganic proton exchange membranes," Journal of Power Sources, vol. 195, no. 13, pp. 3990-3995, 2010.

[28] H. Strathmann, "Electrodialysis and related processes," in Membrane Separation Technology-Principles and Applications, R. D. Nobe and S. A. Stern, Eds., pp. 214-278, Elsevier Science, Amsterdam, Netherlands, 1995.

[29] A. Navarro, C. Rio, and J. L. Acosta, "Pore-filling electrolyte membranes based on microporous polyethylene matrices activated with plasma and sulfonated hydrogenated styrene butadiene block copolymer. synthesis, microstructural and electrical characterization," Journal of Polymer Science Part B: Polymer Physics, vol. 46, no. 16, pp. 1684-1695, 2008.

[30] T. S. Sørensen and M. Dekker, Surface Chemistry and Electrochemistry of Membranes, CRC Press, New York, NY, USA, 1999. 

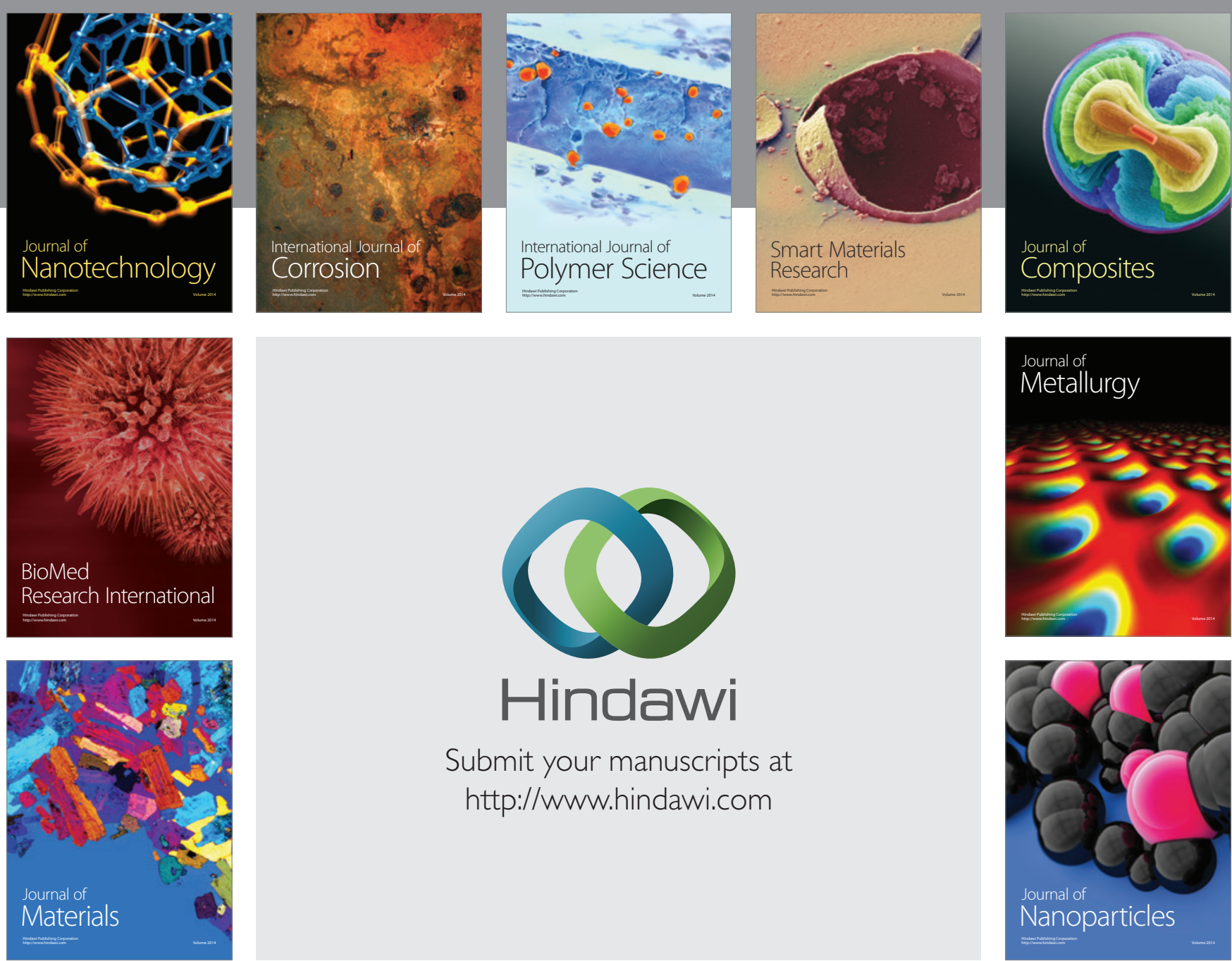

\section{Hindawi}

Submit your manuscripts at

http://www.hindawi.com

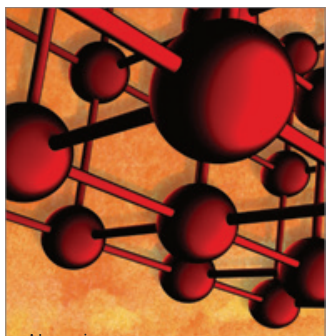

Materials Science and Engineering
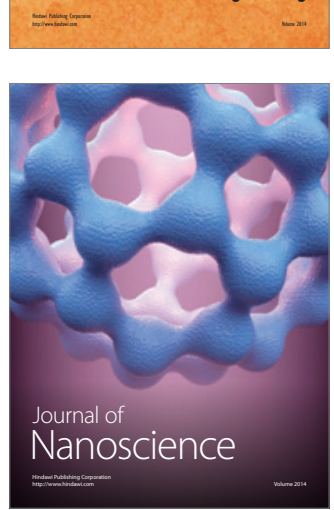
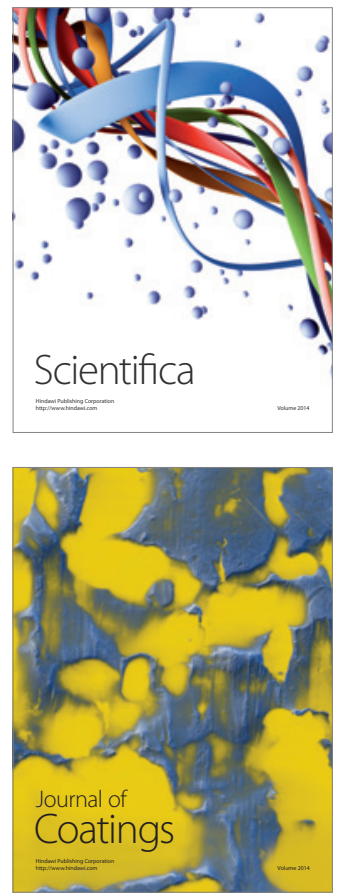
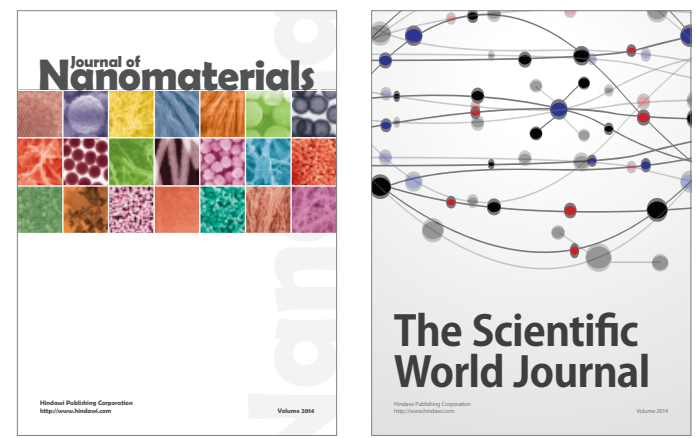

The Scientific World Journal
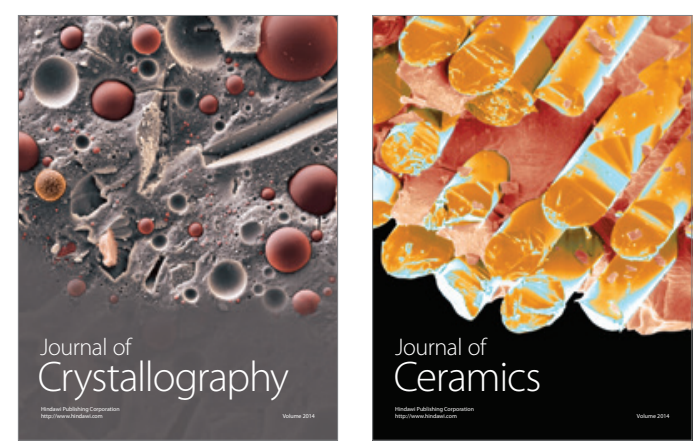
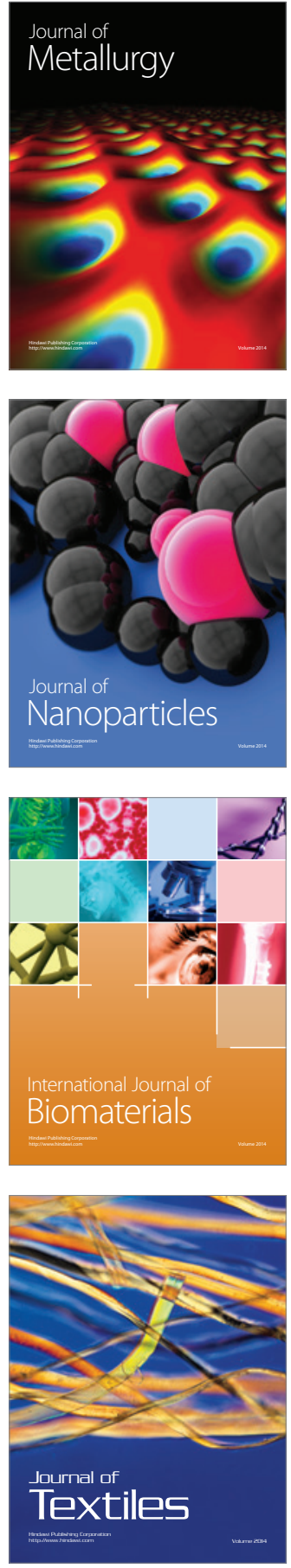